\title{
Community directed approach beyond ivermectin in Tanzania: a promising mechanism for the delivery of complex health interventions
}

\author{
P. MUTALEMWA ${ }^{1 *}$, W.N. KISINZA², W.J. KISOKA ${ }^{3}$, S. KILIMA ${ }^{3}$ J. NJAU ${ }^{4}$, F. TENU ${ }^{2}$, \\ T. NKYA ${ }^{2}$ and S.M. MAGESA ${ }^{2}$ \\ ${ }^{1}$ Tabora Medical Research Centre, P. O. Box 482, Tabora, Tanzania \\ ${ }^{2}$ Amani Medical Research Centre, P. O. Box 81, Muheza, Tanzania \\ ${ }^{3}$ National Institute for Medical Research, P. O. Box 9653, Dar es Salaam, Tanzania \\ ${ }^{4}$ Ifakara Health Institute, P. O. Box 78373, Dar es Salaam, Tanzania
}

\begin{abstract}
The Community Directed Intervention (CDI) is currently used for Ivermectin distribution for the treatment of onchocerciasis in Africa. This study was carried out to determine the extent to which the CDI process can be used for the delivery of other health interventions with different degrees of complexity. The study was conducted in five districts of Kilosa, Muheza, Lushoto, Korogwe and Ulanga in Tanzania and involved communities, health facility and district healthcare providers. Implementation of CDI across these health interventions involved addressing six major processes, namely, stakeholder processes, health system dynamics, engaging communities, empowering communities, engaging CDI implementers and broader system effects. Community and health systems changes were triggered, such that the inherent value of community involvement and empowerment could be internalized by communities and health workers, leading to a more receptive health system. The CDI process was accepted at the community levels as many were willing and ready to adopt the approach. Health workers at community levels were readily available and supportive of the process. Additionally, noted were the verified willingness and ability of community implementers to deliver multiple interventions; confirmed efficiency of CDI leading to cost savings at health systems level; increasing interest of the health system in CDI; interest of health workers in the process of integrated planning. However, there were factors that may have a negative influence on the CDI process. Drug and supply policy for CDI process was lacking at the national and district levels and the presence of parallel community-based programmes that provide financial incentives for community members to run them discouraged Community-directed distributors who in most cases are volunteers. In conclusion, the results have clearly and evidently demonstrated the potential of CDI approach for effectively and efficiently control of other diseases such as malaria, tuberculosis and childhood illnesses. The study has provided unique information on the feasibility and effectiveness of integrated delivery of interventions at the community level.
\end{abstract}

Key words: Community, interventions, malaria, tuberculosis, vitamin A, Tanzania

\section{Introduction}

A critical challenge for onchocerciasis control is the delivery of annual Ivermectin treatment to all target communities and sustaining high treatment coverage over a very long period. To achieve this, the African Program for Onchocerciasis Control (APOC) adopted the strategy of community-directed treatment with Ivermectin (CDTI) in the mid-1990s (TDR, 1996). The CDTI strategy has since been widely recognized as instrumental to the tremendous progress achieved in the control and elimination of onchocerciasis (Amazigo et al., 2007). On the grassroots level, Ivermectin treatment is popular and communities have responded enthusiastically to the concept of community directed intervention in which they themselves are in charge of its planning and implementation (TDR, 1996; Amazigo et al., 2007).

National and international policymakers are therefore increasingly interested in how the CDTIapproach mightbeapplied tointerventions against other diseases (Homeida et al., 2002). This interest provides an important opportunity and momentum to integrate Ivermectin treatment with other disease control activities and to contribute to health care development for some of the poorest populations in Africa. But to ensure that this opportunity is properly exploited, there

* Correspondence: Prince P. Mutalemwa; E-mail: pmutalemwa@nimr.or.tz 
is an urgent need for good scientific evidence on the effectiveness of the CDTI process for interventions against other diseases, as well as evidence regarding effectiveness of integrated disease control at the community level.

Many new interventions fail to produce results when transferred to communities in developing countries, largely because their implementation is untested, unsuitable or incomplete (Madon et al., 2007). For example, rigorous studies have shown that appropriate use of insecticide-treated bed-nets (ITN) can prevent malaria, yet in 2002, fewer than $10 \%$ of children in 28 sub-Saharan African countries regularly slept under bed-nets (Monasch et al., 2004). Interventions such as directly observed treatment, short-course (DOTS) in tuberculosis control, and prophylactic antiretroviral therapy and replacement feeding in prevention of mother-to-child transmission of HIV, may work well in hospitals and clinics. However, in the case of rural areas where people have limited access to formal health care, increasing coverage for control and prevention of many major diseases may require novel approaches.

Community participation is a key principle in Primary Health Care. The Alma Ata Declaration stressed the importance of Primary Health Care in achieving the overall goal of "Health for All". In the Primary Health Care paradigm, disease control programs are to be rooted in communities and are supposed to serve the health and disease control needs of members of the community. This increases the access of community members to health care services and provides them with more opportunities to participate actively in the design of such services, from planning to execution. Such community involvement and participation also are understood to generate a greater sense of ownership over, and sustainability of, various disease control activities.

CDTI is based on the principle of active, structural community participation (TDR, 1996; Brieger, 2000; Remme, 2004), consistent with the aforementioned definitions and goals of primary health care (PHC) provision for sustainable development (Amazigo et al., 2007). In the CDTI process, the community itself plans and carries out treatment of its members. The process empowers community members to make major decisions and direct the distribution of Ivermectin for a sustained period of years. Examples of community decisions made with respect to mass treatment include: dates of distribution; mode of distribution; persons who will guide distribution; and selection of the community implementers, also known as community-directed distributors(CDDs). In addition to making such planning decisions, communities take responsibility for conducting a community census; collecting drug supplies; mobilizing members during the drug distribution process, as well as recording treatments provided and coverage attained (Amazigo et al., 2002). Studies have thus demonstrated the success of this strategy in not only ensuring equity and wider coverage among community members, but also sustainability (Akogun et al., 2001).

The success of CDTI in onchocerciasis control has drawn the attention of other disease control programmes, stimulating various attempts to duplicate CDTI systems and structures for other health interventions. A preliminary assessment indicated that a large number of CDDs are already involved in other health and development activities (Okeibunor et al., 2004). However, since CDTI is based on a well-articulated system of community involvement and participation (Brieger, 2000), such ad hoc and informal participation of other health programmes in the CDTI process may also encounter difficulties -for reasons ranging from poor conceptualization, to problems with practical initiation, implementation and sustainability. Other health programmes also may lack genuine support for a participatory process by health workers and health managers, or they may operate incentive systems that do not encourage volunteerism along the model of CDTI (Walsh \& Warren, 1979; Brieger et al., 1997; Schwab \& Syme, 1997). Furthermore, diseases differ in terms of their complexity of treatment and their overall suitability to the CDTI process. This makes it imperative to systematically examine what other interventions or health programmes might most successfully be integrated into a community-directed delivery process. In response to the need for systematic examination of how CDTI could be harnessed to other health interventions, a new paradigm of community-directed interventions (CDI) was therefore defined. In the CDI concept, the health services and its partners introduce in a participatory manner the range of possible interventions that could be potentially delivered through CDI, and the means by which the community-directed concept can ensure community ownership. From then on, the community takes charge of the process, usually through a series of community meetings for decision-making on implementation. 
This is part of the current multi-country studies to determine the extent to which the CDI process, currently used for Ivermectin treatment of onchocerciasis in Africa can be used for the delivery of other health interventions with different degrees of complexity. Specifically, the study sought to (i) document the CDI process for the integrated delivery of Ivermectin treatment, Vitamin A, ITN, DOTS and Home Management of Malaria; (ii) determine the effectiveness of the CDI process for the delivery of interventions with different degrees of complexity; (iii) identify the critical factors that facilitate or hinder the CDI process and integration from achieving the desired outcomes for the interventions.

\section{Materials and Methods}

\section{Study areas and population}

The study was conducted in two regions in Tanzania, namely Tanga and Morogoro where a total of five districts were chosen on the basis of onchocerciasis endemicity and with APOC supported projects. In Tanga, three districts namely, Lushoto, Korogwe and Muheza were involved. In Morogoro, two districts, namely Kilosa and Ulanga were included in the study. The study area has been extensively described by Kisinza et al. (2008).

\section{Study population and design}

This was a prospective operational research design that employed assessment of preand post-intervention situations, thus giving elements of experimentation (with intervention and control arms) in the study. Elements of case study research were also included in that full documentation of intervention processes and responses were undertaken to ensure full description of how the CDI approach operates.

The target population for the study, in all the districts, included the stakeholders in the intervention processes. These include intervention programme managers, policy makers at the different levels of the delivery of the intervention, community leaders and their volunteers as well as household members in the respective study communities.

Ten communities from each district were randomly selected making a total of 50 communities from where five households were randomly selected to obtain a total of 250 households.

\section{Intervention and evaluation process}

During the intervention process, the roles of the community members were to collectively discuss the prevailing health problems from their own perspective, as well as possible interventions, taking into account relevant community knowledge and additional information provided by the district health team. Specifically the roles were to (1) collectively design the approach to implementing the intervention in the community and identify the resources within the community, (2) collectively plan how, when, where and by whom to implement the intervention, supervise and decide what support to provide to the implementers and how to monitor the process, (3) select a member of the community who will provide the service and be directly responsible to the community in implementing the intervention plan, and (4) collectively discuss the results of the monitoring and adjust the implementation strategy accordingly

The implementation was proceeded by meetings with key stakeholders at all levels (national, district and community). Representatives from all national disease control programmes were included in the planning and implementation meetings. These included the National Malaria Control Programme, National Tuberculosis and Leprosy Programme, National Onchocerciasis Control Programme and Vitamin A Supplementation Programme. The districts were represented by the Council Health Management Team and Focal persons of each of the CDI target interventions. The meeting provided an opportunity to update the district teams on the CDI process and their roles in the implementation. District commitment was made, with a clear understanding of what is expected from them. Support was provided for the teams to put together a framework for their respective district CDI plans.

Having concerted with the community leadership, the next step was meeting with entire communities at mass meetings. During these meetings, the information and much of the process was discussed with the community leaders where emphasis was placed on mobilization and sensitization of communities on the benefits of the intervention(s). The Community Directed Distributors (CDDs) as well as community leaders were trained on the methods of service delivery. Community leaders were responsible to ensure that CDDs adhere to treatment regulations and compliance to the exclusion criteria to community members. Key indicators used for the evaluation on the success of CDI process were factors that facilitate or hinder the CDI approach for integrated delivery of interventions with different degrees of complexity. 


\section{Data management and analysis}

A conceptual framework was hypothesized to describe qualitative factors in the CDI process. Qualitative data entry and analysis employed standard word processing programmes as well as Atlas.ti version 5.5.

\section{Results}

\section{Stakeholders process and mobilisation}

Prior to incepting CDI activities, there were stakeholders' feedback meetings at the national, district and community levels. It was important to have the description of the current efforts in different levels as this was the key for community programming. The main focus of these meetings was to build capacities of mounting and managing the CDI process and hence improve the basic health foundations of the communities. The national coordinators of targeted health programmes, supporting partners as the main stakeholders were sensitized at their level. This was followed by the same process at the district and then community levels where district programme coordinators of the targeted health interventions as well as community leaders presented opinions of the CDI process and thereby discussing emerging challenges which might lead to the success or failure of the approach. There was a strong support of the process at the national, district and community levels. At all levels, successful advocacy and mobilization were accrued regarding the delivery of specific interventions hence showing high acceptance of the process.

\section{Stakeholders' mobilization}

At the national level advocacy meetings were conducted in order to provide feedback and rectify where successes were not recorded. Coordinators of the study interventions committed their support to facilitate all operations and their attitudes towards CDI process were very high. Stakeholders meetings at the district level were held in each study district and plans on when and how to inceptCDI interventions were discussed. Such meetings included focal persons of the interventions, study team, Non-Governmental Organizations and Non-Governmental Development Organizations supporting disease control in the study districts.

Efforts to develop the planning processes at the community level emphasized grassroots decision making hence a need for lower level communityadvocacy and sensitization meetings. Meetings were held with community leaders and all members of the study communities which were facilitated by district health staff. Disease focal persons for the different interventions introduced the interventions and mode of adding new interventions to existing ones were discussed thoroughly. In all districts, the issue of remuneration was widely discussed by community members basing on the fact that currently existing CDDs do not have any package to facilitate the operations.

\section{Health systems dynamics}

Disease control programmes of the study interventions were supportive from the national to the district levels. National Coordinators of Malaria, Tuberculosis, Expanded Programme on Immunisation and Onchocerciasis as well as district focal persons of the respective interventions took part in planning meetings where the study protocol, roles and responsibilities of each party were discussed. Additionally district focal persons trained the implementers who were selected in the study communities. Frontline Health Facilities (FLHF) and staff in all study districts were willing to support the CDI process and in each community whenever training was being conducted, the FLHF staff and with district focal persons took part in training the selected implementers. Health care facilities were destinations for drug storage where implementers collected drugs for distribution.

"I am heading this facility and all implementers report to me when there are problems in their day to day operations. During national immunisation day and Ivermectin distribution, it is my responsibility to preserve drugs and manage the distribution in collaboration with with the CDDs who in turn have to report back to me when stock out is experienced" (Health Worker, Daluni Dispensary, Muheza).

Key issues that were raised as being important in sustaining the CDI process among others were motivating the CDI implementers. Methods of incentives that were proposed were non-monetary including gifts and exemption from community duties. Moreover, many leaders and community implementers who were interviewed had positive attitude that such incentive could have visible implications on the disease management process. They hence proposed that a clear policy for motivating the implementers be set up to raise CDI implementers' attitude and hence improve 
their performance. While some disease control programmes were willing to provide resources for CDI, there were no clear procurement and supply policies within the programmes for free delivery of products and supplies. For instance, in all the study districts, there was no free provision of nets. Moreover, the study had no access to ITNs or re-treatment kits to be provided through alternative channels and this hampered the implementation of the CDI scheme. In all districts, except Kilosa, ivermectin distribution and delivery of the study interventions was integrated in normal/routine activities. Critical factors that influenced the implementation process of CDI process are summarized in Table 1. of community-directed approach and political leadership (Table 2). Better geographical accessibility to the community led to successes of the CDI process. Implementers worked in communities where households were largely scattered. In addition, they needed transport meansin order toacquire materials from frontline health facilities. Elsewhere, health workers had to access communities for supervision as well maintaining communication with the districts headquarters. All study districts however, were easily accessible throughout the year with little interception during rainy seasons.

In this study participatory approaches

Table 1: Critical factors that influenced the implementation of CDI process

\begin{tabular}{|c|c|c|c|c|c|c|}
\hline Critical factors & Kilosa & Lushoto & Muheza & Korogwe & Ulanga & $\begin{array}{l}\text { Overall } \\
\text { score }\end{array}$ \\
\hline $\begin{array}{l}\text { Existence of procurement and } \\
\text { supply policy }\end{array}$ & High & Low & Low & Low & High & Low \\
\hline $\begin{array}{l}\text { Support from the Ministry of } \\
\text { Health }\end{array}$ & Very High & Very High & Very High & Very High & Very High & Very High \\
\hline $\begin{array}{l}\text { Support from the Frontline } \\
\text { Health Facilities }\end{array}$ & Very High & Very High & Very High & Very High & Very High & Very High \\
\hline $\begin{array}{l}\text { Health workers attitudes, } \\
\text { motivation and outreach }\end{array}$ & High & High & High & High & High & High \\
\hline $\begin{array}{l}\text { Competing vertical } \\
\text { program and } \\
\text { strategies, including the } \\
\text { informal sector }\end{array}$ & Moderate & Low & Low & Low & Low & Low \\
\hline
\end{tabular}

\section{Engaging communities}

In the CDI process the main point of contact with these communities was the FLHF workers and community leaders. However, there were important factors that made community engagement successful and these were the yearround geographical accessibility of community, participatory approaches to community mobilization, community perception of value of interventions, community perception of value to sensitize and mobilize communities were used. There were community meetings with community leaders where roles and responsibilities of leaders were collectively discussed. These were followed by public meetings involving all members of the communities. District focal persons for the different interventions introduced their interventions and all parties expressed the commitment to CDI process. On addition to

Table 2: Critical factors in engaging communities in CDI process

\begin{tabular}{lllllll}
\hline Critical factors & Kilosa & Lushoto & Muheza & Korogwe & Ulanga & $\begin{array}{l}\text { Overall } \\
\text { score }\end{array}$ \\
\hline $\begin{array}{l}\text { Year-round geographical } \\
\text { accessibility of community }\end{array}$ & High & High & High & High & Moderate & High \\
$\begin{array}{l}\text { Participatory approaches to } \\
\text { community mobilization }\end{array}$ & $\begin{array}{l}\text { Very } \\
\text { high }\end{array}$ & $\begin{array}{l}\text { Very } \\
\text { high }\end{array}$ & $\begin{array}{l}\text { Very } \\
\text { high }\end{array}$ & Very high & Very high & Very high \\
$\begin{array}{l}\text { Community perceives value of } \\
\text { interventions }\end{array}$ & High & High & High & High & High & High \\
$\begin{array}{l}\text { Community perceives value of } \\
\text { community-directed approach }\end{array}$ & High & High & High & High & High & High \\
$\begin{array}{l}\text { Political leadership in } \\
\text { communities }\end{array}$ & High & High & High & High & High & High \\
\hline
\end{tabular}


that the need of selecting or using the same implementers with experience in keeping records and/or management of possible side effects were discussed and agreed upon. Communities expressed general willingness to participate in CDIschemes on the basis of success achieved from the CDTI. The results revealed that community members were involved in decision making through public meetings as some members reported in the focus group discussions. The community perception of CDI intervention was another critical factor in the success of the process. Communities had clear understanding on the CDI intervention. This perception was expressed in term of the benefits peopleachieved throughCDIinterventions. They claimed that the process is cheap and accessible to all members of the community. In Lushoto district there was an overwhelming acceptance towards CDI interventions particularly CDTI where improved health status of the community members raised the income as they could well participate more in various economic activities. Elsewhere it was pointed out that time spent for seeking medical care was minimized because providers are currently with their communities. It was further observed that free drug delivery saves accrued income which is now spent on other family demands.

"We are happy because we are given drugs freely every year and services are closer to us. We do not have to go to health facilities for these drugs. This is one of the benefits we get from this programme" (Community member, Melees village, Ulanga District).

Positive perception towards the value of CDI interventions in terms of decline in disease burden was expressed during focus group discussions. Community members pointed out that CDTI was successful in reducing the morbidity of Onchocerciasis. Generally, there were positive expressions of the value of the interventions across the study districts depicting the success of the CDTI process where community members had an upper hand in the decision making process. Communities expressed general interest and willingness to participate in CDI process basing on the fact that the the whole process is community based. The driving force of their expectations was the readily accessibility to health care services and eventual improvement of their health status. In most sites there was general acceptance of CDI and acknowledgement of its public health value among the affected populations.
"CDI is a very good programme, because the community itself decide who should be the implementers and why. We take part in selecting the implementers, whom we believe have adequate time and are willing to serve the community" (Community member, Mnyuzi village, Korogwe district).

Involvement of community was essential to programme success. Political leaders (Village Executive Officers, Village Chairpersons and Sub-village Chairpersons) were essentially involved in all decision making processes and were pivotal in the success of the process. Their involvement was a key component in linking community members to the districts' health systems, from facility to national level.

\section{Empowering communities}

In genuinely empowering communities, members developed ownership of the CDI process and this led to more commitment to it and hence achieving the desired goals. Most of intervention processes were engineered at the sub-village level which is the lowest stage of administration. It is at this level where information regarding CDI process was widely distributed to community members. Roles and responsibilities of leaders, implementers and community members were described. There were also public meetings involving all members of the communities which were facilitated by district health staff. During all meetings, district focal persons for different interventions introduced their interventions and where necessary health education and promotion strategies were emphasized.

Community members were more willing to take on the CDI approach because of the tangible outcomes that were largely experienced not only on CDTI but also for other diseases such as lymphatic filariasis. Community members showed much interest on the preventive measures by CDI approach because of the reduced economic burdens especially when drugs are freely given and within their households. Thus saving time and money.

"We thank our health officials who brought these interventions because many people are now healthy and can proceed with daily activities not as it was before" (Community Drug Distributor, Zombo Kwa Tupa, Kilosa District).

During advocacy and mobilization meetings at the community levels, roles and responsibilities of community members, leaders, 
implementers and health workers in the CDI process were clearly stipulated and agreed upon by each party. The whole process which was participatory in nature stimulated the support from all parties and all expressed the willingness to support each other during the interventional phase. Community implementers appreciated the trust they were accorded by community members and at the same time members acknowledged the positive outcome of the implementers.

"We appreciate them because they are committed and treat us with love and respect although they are not paid" (Village Executive Officer, Maramba, Muheza District).

Selection, training and motivation of implementers have been among others, the important key issues to sustain the CDI approach. It was the community members (in the sub villages) who selected implementers with basic characteristics set up by themselves. After selection, training on all four health interventions was initiated and supervised by district health personnel. experience, and motivation by extrinsic and intrinsic incentives.

Community implementers expressed general willingness to participate in CDI schemes on the basis of expectations to benefit from the interventions. In all districts CDDs who were selected since the first phase showed willingness of continuing with activities for phase three. Selections of implementers in all study districts were done during community meetings and the main criteria were skill, experience with previous programmes (particularly CDTI), literacy level, gender, selfhelp spirit as wellasgeneralacceptance in their areas of domicile (Table 3). Generally it was observed that the community implementers showed great ability and anxiousness to take up new responsibilities especially when new interventionswereintroduced.Accredited training by Frontline Health workers, focal persons for specific intervention assisted in imparting skills to support their engagement and commitment. Community members doubted on the continued performance of the implementers as long as they

Table 3: Basic characteristics used in the selection of the implementators

\begin{tabular}{|c|c|c|c|c|c|c|}
\hline Characteristic & Kilosa & Lushoto & Muheza & Korogwe & Ulanga & $\begin{array}{l}\text { Overall } \\
\text { score }\end{array}$ \\
\hline Information sharing & Very high & Very high & High & High & Very high & Very high \\
\hline $\begin{array}{l}\text { Community interest in CDI } \\
\text { focal issues }\end{array}$ & Very high & Very high & Very high & Very high & Very high & Very high \\
\hline $\begin{array}{l}\text { Help Spirit as related in } \\
\text { community ownership }\end{array}$ & High & Very high & Very high & Very high & Moderate & High \\
\hline $\begin{array}{l}\text { Trust among community } \\
\text { members }\end{array}$ & Very high & High & Very high & Very high & High & Very high \\
\hline $\begin{array}{l}\text { Community selection of CDI } \\
\text { implementers }\end{array}$ & Very high & Very high & Very high & Very high & Very high & Very high \\
\hline
\end{tabular}

\section{Engaging CDI implementers}

The process of engaging implementers involved selecting, training and motivating CDDs and that was a key approach to sustain the CDI process. Critical factors that either enabled or hindered that process at its various stages included willingness to take initiative, selection by community, skills/ do not have a clear policy to motivate them. This was pointed out as a possible drawback to the performance of the CDI process in general. All CDDs were accepted and members proposed that the same CDDs may be used when a new integrated delivery of the implementation was being adopted.

\section{Table 4: Critical factors on engaging community implementers}

\begin{tabular}{|c|c|c|c|c|c|c|}
\hline \multirow{2}{*}{$\begin{array}{l}\text { Critical factors on } \\
\text { engaging communities }\end{array}$} & \multicolumn{5}{|c|}{ Levels of importance based on process data } & \multirow{3}{*}{$\begin{array}{l}\begin{array}{l}\text { Overall } \\
\text { score }\end{array} \\
\text { Very high }\end{array}$} \\
\hline & Kilosa & Lushoto & Muheza & Korogwe & Ulanga & \\
\hline $\begin{array}{l}\text { Willingness to take } \\
\text { initiative }\end{array}$ & Very high & Very high & Very high & Very high & Very high & \\
\hline Selection by Community & Very high & Very high & Very high & Very high & Very high & Very high \\
\hline $\begin{array}{l}\text { Skills and relevant } \\
\text { Experience }\end{array}$ & High & High & High & High & High & High \\
\hline $\begin{array}{l}\text { Motivation by extrinsic } \\
\text { and intrinsic incentives }\end{array}$ & Low & Low & Low & Low & Low & Low \\
\hline
\end{tabular}




\section{Broader systems effects}

In Tanzania through CDI there was growing awareness of women to participate in the same position as there were women who were in the formal power networks (women leaders). Elsewhere selection of CDDs considered gender because there was an equal opportunity for men and women who were selected as drug distributors in each hamlet. The selection of CDDs increased women representative in CDI activities.

"This programme values the contribution of women in the community. This is good because women are hard working and we always appreciate them" (District Key Informant, Lushoto). In Kilosa district, a village leader at Zombo Playa had these to add: "CDTI selection considers gender balance whereby from each hamlet there are supposed to have two CDDs, a man and a woman"

Much of the community action towards disease control had the goal of reducing health problems by encouraging community participation in local disease control strategies. It was worth to note that there were some community actions using CDI approach in the fight against some of the neglected diseases. In Lushoto, Korogwe and Muheza impact of the interventions on Lymphatic filariasis and Onchocerciasis on development were described.

Monthly supervisory activities by district teams were done. The district teams engaged Frontline Health staff and implementers in monitoring the CDI process. During such outreach services CDD were involved as partners and where necessary existing problems as related to CDI were rectified. It was during such supervision activities where health personnel met with village leaders and health priorities were discussed and identified to be included in Comprehensive Council Health Plans.

\section{Discussion}

Implementation of CDI across five health interventions involved addressing major processes, which were regarded as having relatively equal importance to outcomes. These are stakeholder processes; health system dynamics; engagement of the communities; community empowerment; engagement of CDI implementers; and broader system effects. Involvement of community is essential to programme success and a key component in coordinating community members to the districts' health systems starting at the Frontline
Health Facilities up to the national level. Such involvement reveals that community factions and other coordinating groups of decision making may be critical for any health program's success. It is rightly clear that when genuinely empowered in participatory health projects, community members develop awareness and ownership of the program and build commitment to local action especially at a point when they are involved as partners on every stage (Mlozi et al., 2006). Collaboration is fostered and local empowerment is realized through the marshalling of community interest, talent and resources.

Findings from the study show that the most critical factors that might facilitate the CDI process are, extensive stakeholder consultation whereby and consensus to all interventions is extensivelybuilt, problem-solvinghealthpolicies that support community-based delivery of the interventions, broad health systems support to community empowerment, community engagement in the design and implementation of CDI and higher community involvement especially in selecting the community based drug distributors. The study has provided unique information on the feasibility and effectiveness of integrated delivery of interventions at the community level. Integrated delivery of different interventions through the CDI process proved perfectly feasible, and based on the lessons learned, such integration will be greatly facilitated by the following factors: proven willingness and ability of community implementers to deliver multiple interventions, proven efficiency of CDI leading to cost savings at health systems level, increasing interest of the health system in CDI, interest of health workers in the process of planning integrated, community-based interventions, motivation of health workers by positive feedback from the community, increasing interest and openness of stakeholders to integrated approaches.

While findings have indicated that when given the opportunity and necessary support, communities and community implementers could effectively implement each of the five study interventions, irrespective of their level of complexities; there were some technical limitations that prevented implementation by community volunteers. The first limitation that was noted has been poor motivation to communityimplementers. Communitymembers doubted on the continued performance of the implementers as long as they do not have a clear policy to motivate them $(\mathrm{MoH}, 2007)$. It is very 
clear that these implementers are volunteering but when highly motivated their performance can be enhanced.

The second limitation was the issue of procurement and supplies. There were no clear procurement and supply policies within those health interventions in focus as related to free delivery of products and supplies. In Tanzania for instance where malaria is a number one health problem, free provision of anti-malarial drugs at community levels would have facilitated the CDI process. Throughout the study districts, there was no free provision of nets as this was not the policy for net distribution during the study period. However, there have been now the global initiatives of free provisions of treated bed-nets in malaria endemic countries including Tanzania aiming at high coverage for malaria control. Such initiatives are very important as the problem of supplies that was noted during the study could ultimately be resolved.

Rooted in the study results, it is recommended that in areas with experience in community-directed treatment for onchocerciasis control, the CDI approach should be used for integrated community level delivery of a broader range of appropriate health interventions. This was attested by the interventions in this study, especially for malaria, Vitamin A supplementation, TB or other packages. Noting this success it may generally be concluded that the CDI process is an appropriate model for the delivery of health interventions that have the following characteristics: (a) interventions for which the community can be engaged and empowered to take control of implementation; (b) interventions for which the health system agrees to empower communities for implementation; (c) interventions that can be adequately delivered by lay health workers without extensive training; (d) interventions for diseases perceived as an important health problem that affects all sections of the community; (e)interventions that have a clearly perceived benefit and (f)interventions for which materials are expected to be adequately accessible to the community.

Received 05 February 2009

Revised 15 June 2009

Accepted 16 June 2009

\section{References}

Akogun, O.B., Audu, Z., Weiss, M.G., Adelakun, A.O., Akoh, J.I., Akogun, M.K., Remme.
J.H.F. \& Kale O.O (2001). Communitydirected treatment of onchocerciasis with ivermectin in Takum, Nigeria. Tropical Medicine \& International Health 6, 232-43.

Amazigo, U., Okeibunor, J., Matovu, V., Zoure, H., Bump, J. \& Seketeli, A. (2007). Performance of predictors: evaluating sustainability in community-directed treatment projects of the African programme for onchocerciasis control. Social Science E Medicine 64, 2070-2082.

Amazigo, U.V., Obono, M., Dadzie, K.Y., Remme, J.H.F., Jiya, J., Ndyomugyenyi, R., Roungou, J.B., Noma, M. \& Seketeli, A. (2002) Monitoring communitydirected treatment programmes for sustainability: lessons from the African Programme for Onchocerciasis Control (APOC). Annals of Tropical Medicine and Parasitology 96 Supplement 1, S75-92.

Brieger, W.R. (Ed.) (2000) Implementation and sustainability of community-directed treatment of onchocerciasis with ivermectin. Geneva, UNDP/World Bank/WHO Special Programme for Research and Training in Tropical Diseases.

Brieger, W.R., Otusanya, S., Adeniyi, J.D., Tijani, J. \& Banjoko, M. (1997) Eradicating guinea worm without wells: unrealized hopes of the Water Decade. Health Policy Plan, 12, 354-362.

Homeida, M., Braide, E., Elhassan,E. Amazigo,U. V., Liese, B., Benton, B., Noma, M., Etya'Ale, O., Dadzie, K.Y., Kale, O.O. \& Seketeli, A. (2002) APOC's strategy of community-directed treatment with ivermectin (CDTI) and its potential for providing additional health services to the poorest populations. African Programme for Onchocerciasis Control. Annals of Tropical Medicine and Parasitology, 96 (Suppl1), S93-104.

Kisinza, W.N., Kisoka, W.J., Mutalemwa, P.P., Njau, J., Tenu, F., Nkya, T., Kilima, S.P. \& Magesa, S.M.(2008)Community directed interventions for malaria, tuberculosis and Vitamin $\mathrm{A}$ in onchocerciasis in endemic districts of Tanzania. Tanzania Journal of Health Research 10, 232-239.

Madon, T., Hofman, K.J., Kupfer. L. \& Glass, R.I. (2007) Public health Implementation science. Science 318, 1728-9. 
Mlozi, M.R.S, Shayo, E.H., Senkoro, E.H., Mayala, B.K., Rumisha, S.F., Mutayoba, B., Senkondo, E., Maerere, A. \& Mboera, L.E.G. (2006) Participatory involvement of farming communities and public sectors in determining malaria control strategies in Mvomero District, Tanzania. Tanzania Health Research Bulletin 8, 134140.

$\mathrm{MoH}$ (2007) Primary Health Services Development Programme (PHSDP)/ Mpango wa Maendeleo wa Afya ya Msingi (MMAM) 2007 -2017. Ministry of Health and Social Welfare, The United Republic of Tanzania.

Monasch, R., Reinisch, A., Steketee, R.W., Korenromp, E.L., Alnwick, D., \& Bergevin, Y. (2004) Child coverage with mosquito nets and malaria treatment from population-based surveys in African countries: a baseline for monitoring progress in roll back malaria. American Journal of Tropical Medicine and Hygiene 71, 232-238.

Okeibunor, J.C., Ogungbemi, M.K., Sama, M.,
Gbeleou, S.C., Oyene, U. \& Remme, J.H.F. (2004) Additional health and development activities for communitydirected distributors of ivermectin: threat or opportunity for onchocerciasis control? Tropical Medicine $\mathcal{E}$ International Health, 9, 887-896.

Remme, J.H.F. (2004) Research for control: the example of onchocerciasis. Tropical Medicine E International Health, 9, 243254.

Schwab, M. \& Syme, S.L. (1997) On paradigms, community participation, and the future of public health. American Journal of Public Health, 87, 2049-2051.

TDR (1996) Community-Directed Treatment with Ivermectin: Report of a Multi-Country Study. Special Programme for Research and Training in Tropical Diseases, World Health Organization Geneva.

Walsh, J.A. \& Warren, K.S. (1979) Selective primary health care: an interim strategy for disease control in developing countries. The New England Journal of Medicine, 301, 967-974. 